\title{
Susceptibility of pear cultivars to entomosporiosis
}

Thiago Marchi, Ires Cristina Ribeiro Oliari, Anna Claudia Oliveira, Aline José Maia, Rafael Piva, Renato Vasconcelos Botelho*

State University of the Midwest, Guarapuava, PR, Brazi

*Corresponding author, e-mail: rbotelho@unicentro.br

\begin{abstract}
The entomosporiosis is considered a major disease of pear in Brazil, one of the most responsible for premature defoliation in plants. The objective of this study was to characterize the susceptibility of pear tree cultivars Housui, Cascatense, Packam's Triumph and Rocha for the intensity of leaf spot entomosporiosis. The experiment was conducted at the experimental orchard of the State University of the Midwest (Unicentro), Paraná State, Guarapuava County, Brazil during the $2013 / 2014$ season. The incidence and severity were monitored during 77 days from the beginning of the symptoms in 25 leaves of 8 plants per cultivar. With these data the following variables were calculated: early onset of symptoms (EOS), maximum incidence and severity (Imax and Smax) and the Area Under the Incidence Progress Curve (AUIPC) and Severity (AUSPC). In addition, the data were checked for severity and the best adjustments for the monomolecular, logistic and exponential models were tested. From these results it is clear that all the studied cultivars are susceptible to leaf spot entomosporiosis, however, Housui pear cultivar presented higher endurance while Rocha and Cascatense cultivars presented greater susceptibility to this disease.
\end{abstract}

Keywords: Entomosporium mespili, epidemiology, pathossystem, Pyrus sp

Brazilian fruticulture is known worldwide

as one of the most diversified, but pear crop present poor expression presenting $0.5 \%$ of the temperate climate fruits grown in this country and it is the most imported fresh fruit (Fioravanço, 2007; Fachinello et al., 2011).

With high fruit demand, pear appears as an alternative for orchard diversification of temperate and subtropical regions of Brazil (Bogo et al., 2013). However, this diversification depends directly on the viability of new technologies such as the development of adapted cultivars, rootstock definition, availability of quality seedlings and adequate control of diseases and pests (Fioravanço, 2007; Faoro \& Orth, 2010;
Fachinello et al., 2011; Machado et al., 2013). For Bogo et al. (2013) the high incidence of diseases causes a significant decrease in fruit production and, in some cases, it becomes totally unfeasible.

In this context, the entomosporiosis caused by the fungus Fabraea maculata lev. G.F. Atk. (anamorphic phase: Entomosporium mespili DC Sacc.) represents the main disease of pear crop in Brazil (Gonçalves et al., 2013). The disease affects leaves, branches and fruits. In young leaves, reddish-purple spots up to $3 \mathrm{~mm}$ in diameter may darken with development and exhibit chlorotic halo. In severely attacked leaves, the spots coalesce, reducing the plant vigor. The defoliation in the lower part to the middle part of 
the canopy is considered a typical characteristic of the disease (Bell \& Van Der Zwet, 2005; Rufato et al., 2012; Bogo et al., 2013).

The study of alternative methods of disease management and host interaction are tactics that may contribute entomosporiosis control (Bogo et al., 2013; Gonçalves et al., 2013). Nowadays there are resistant cultivars to this disease, but it is known that some cultivars are more susceptible than others (Bell \& Van Der Zwet, 2005; Gonçalves et al., 2013). This way, the objective of this study was to characterize the behavior of different pear cultivars in relation to the intensity of the leaf spot of entomosporiosis.

The experiment was conducted in the experimental orchard of the State University of the Midwest (Unicentro), Paraná State, Guarapuava County, Brazil at the geographic coordinates $25^{\circ} 23^{\prime} 36^{\prime \prime} S$ and $51^{\circ} 27^{\prime} 19^{\prime \prime} \mathrm{W}$ and nearly $1120 \mathrm{~m}$ above sea level, during the 2013/2014 harvest. The climate is classified as humid mesothermic subtropical (Cfb), without dry season, with fresh summer and moderate winter. The soil of the experimental area is a Dystroferric Latosol. Air temperature, air humidity and rainfall data were made collected by the Meteorological Station of the University.

For data collection, 32 plants were identified, and the disease incidence and severity were evaluated at $0,7,14,21,28,35,42,49,56$, 63 and 77 days after first onset of symptoms. The incidence and severity were evaluated under conditions of natural infection, and the incidence calculated by the percentage of leaves with at least one lesion in relation to the total number of leaves evaluated and the severity was evaluated using the adapted methodology of Llorenti et al. (2010) that attributes the following classes of infection for leaf spots: class 0: no lesions; class 1: 1-5 lesions; class 2: 6-25 lesions and class 3: more than 25 lesions.

Disease severity was calculated using the following formula:

$$
\mathrm{S}=\sum_{n=1}^{N} \operatorname{In} / 3 . \mathrm{N}
$$

Where: $S$ is the severity index (from 0 to 1 ); $I_{n}$ is the severity class on the $n$th leaf; $N$ is the total of leaves evaluated and 3 is the maximum severity level.
With the severity data the adjustments were verified for three empirical mathematical models: $\quad$ Monomolecular $(Y=1-(1-Y 0) \exp (-$ $r t))$, Logistic $(Y=1 /(1+((1 / Y 0)-1) \exp (-r t))$ and Exponential $(Y=Y 0 \exp (r t))$; where: $Y=$ severity $(0$ 1) at time $t, Y O=$ initial disease level and $r=$ rate of disease increment for each empirical model. The adjustment quality was verified by the coefficient determination (R2) and the residue error.

The experimental area was implemented in 2009, with the plants distributed in $4 \times 1 \mathrm{~m}$ spacing and conducted in a central leader system. All cultivars studied were grafted onto the 'CP' quince tree rootstock (Cydonia oblonga). The orchard management was carried out according to organic production standards, without application of synthetic inputs, with inline crop rotation and organic fertilization. During the execution of the experiment no applications of phytosanitary products were performed.

The experimental design was completely randomized with 8 replications, and for each replicate 25 leaves were evaluated. The leaf spot intensity of entomosporiosis was evaluated with time elapsing in four pear cultivars: Housui (Pyrus pyrifolia; of Japanese origin); Packam's Triumph (P. communis; of Australian origin); Rocha (P. communis; Portuguese origin) and Cascatense (P. communis X P. pyrifolia; an hybrid developed by the Genetic Improvement Program of Embrapa Temperate Climate, as a result of crossing Packham's Triumph and Le Conte) (Rufato et al., 2012).

From the data obtained, progress curves were plotted for the disease incidence and severity, and the epidemics were compared in relation to the onset of symptoms (EOS), maximum incidence and severity (Imax and Smax) and Area Under the Incidence Progress Curve (AUIPC) and Severity (AUSPC). The following formula was used to calculate the Area Under the Disease Progression Curve (AUDPC):

$$
A A C P D=\Sigma((Y i+(Y i+1)) / 2)^{*}((+i+1)-t i)
$$

Where: $Y$ is the disease intensity, $\dagger$ time and $i$ the number of assessments in time (Campbell \& Madden, 1990). When significant to the differences by the F test ( $p<0.05$ ), the averages were compared by Duncan test $(p<0.05)$ using the statistical program Assistat version 7.7 beta. 
The Brazilian climate conditions with high temperatures and frequent rainfalls, especially in spring, provide favorable conditions for entomosporiosis development (Bell \& Van Der Zwet, 2005; Gonçalves et al., 2013). Jones and Aldwinckle (1990) reported that the favorable environmental conditions for the occurrence of $E$. mespili infection are temperatures ranging from 14 to $28^{\circ} \mathrm{C}$, with an optimum of $20^{\circ} \mathrm{C}$ and precipitation with peaks above $30 \mathrm{~mm}$. During the conduction of the experiment, seven peaks of ideal precipitation were observed reaching 431 $\mathrm{mm}$ during the study and average temperatures of $15.7,20.8,25.9{ }^{\circ} \mathrm{C}$ and $70.9 \%$ for minimum, medium, maximum and relative air humidity, respectively (Figure 1).

The incidence and severity evolution of entomosporiosis in different pear cultivars can be verified in Figure 2. It is observed that all pear cultivars presented disease symptoms; however, the appearance and development occurred in a different way among the cultivars.

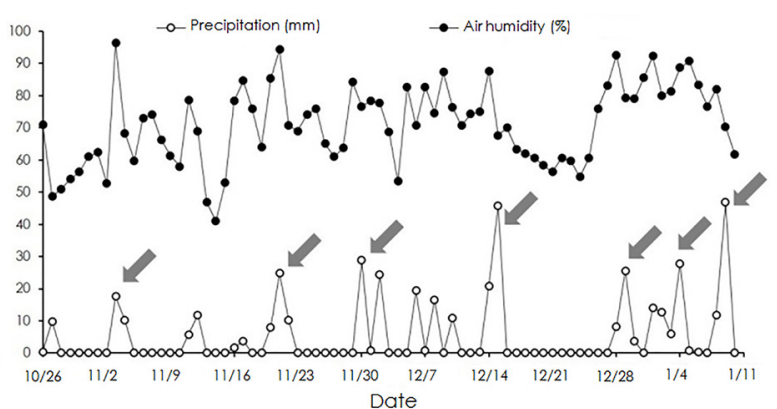

Figure 1. Climatic conditions for air temperature, precipitation and air humidity recorded daily during the execution of the experiment. Guarapuava, Brazil, 2014.

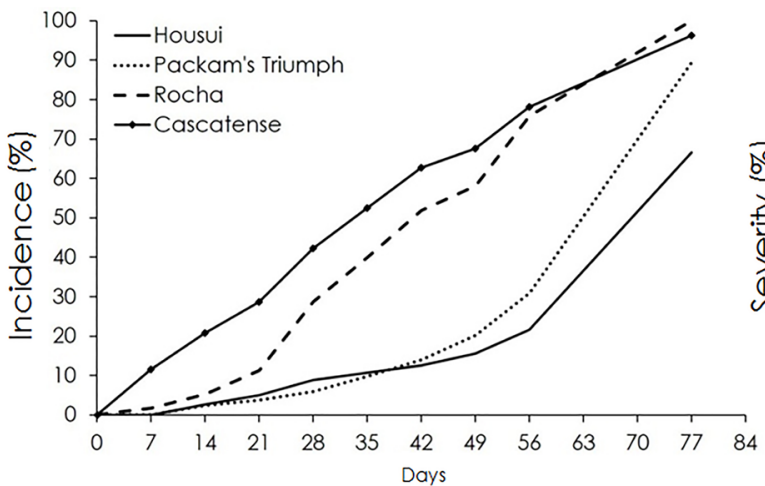

Figure 2. Evolution of incidence and severity of entomosporiosis leaf

The first entomosporiosis symptoms appeared in November. According to Bogo et al. (2013) the source of primary inoculum are ascospores produced on fallen leaves during the winter that are eliminated from apothecials in rainy periods in the late winter-early spring.

The logistic and exponential mathematical models allow the best data adjustment, based on the coefficient of determination $\left(R^{2}\right)$ and residue error (error $(r)$ ) (Table 1). This allows us to infer that the disease increase rate is proportional to the amount of preexisting inoculum (initial inoculum) and infection rate, a characteristic inherent in polycyclic disease systems, such as entomosporiosis (Bogo et al., 2013 ). These results are in agreement with Gonçalves et al. (2013) and Gonçalves

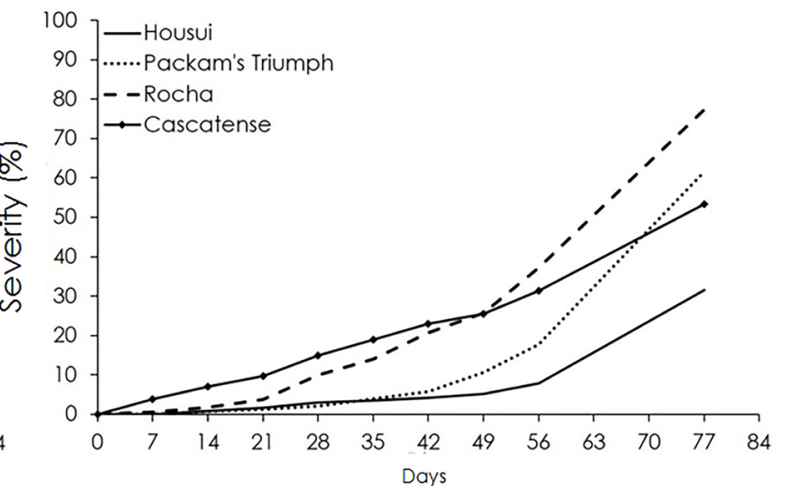

et al. (2014) who showed that the logistic and Gompertz models allow the best fit for the development of entomosporiosis in European pear trees in southern Brazil.

Table 2 shows the epidemiological quantification variables.

Differences in EOS were observed among pear cultivars, and in cv. Cascatense the first symptoms were found in only seven days, whereas in cvs. Housui (33.25 dEOS) and Packam's Triumph (32.38 dEOS) this period was longer (Table 2). The cv. Rocha did not differ from the others, with an average value of 15.75 dEOS. According to Rufato et al. (2012) under conditions of high humidity and temperatures between 20-25 ${ }^{\circ} \mathrm{C}$, leaf spots appear about four to seven dEOS after infection. The delay for 
Table 1. Coefficient of determination $\left(R^{2}\right)$ and residue error (error $\left.(r)\right)$ for entomosporiosis severity evolution in pear cultivars, adjusted to different mathematical models. Guarapuava, Brazil, 2014.

\begin{tabular}{lcclccccc}
\hline \multirow{2}{*}{ Pear cultivar } & \multicolumn{2}{c}{ Logistic } & & \multicolumn{2}{c}{ Monomolecular } & & \multicolumn{2}{c}{ Exponential } \\
\cline { 2 - 3 } & $\mathrm{R}^{2}$ & Error $(\mathrm{r})$ & & $\mathrm{R}^{2}$ & Error $(\mathrm{r})$ & & $\mathrm{R}^{2}$ & Error $(\mathrm{r})$ \\
\hline Packam's Triumph & 0.79 & 0.00134 & & 0.63 & 0.00126 & & 0.79 & 0.009414 \\
Rocha & 0.88 & 0.003552 & & 0.83 & 0.000087 & & 0.87 & 0.003425 \\
Housui & 0.79 & 0.007095 & & 0.69 & 0.000528 & & 0.80 & 0.006002 \\
Cascatense & 0.88 & 0.003031 & & 0.85 & 0.000656 & & 0.88 & 0.001934 \\
\hline
\end{tabular}

Table 2. Early onset of symptoms (EOS), Maximum incidence (Imax), Smaximum severity (Smax) and Area Under the Incidence Progress Curve (AUIPC) and Severity (AUSPC) of entomosporiosis leaf spot in pear cultivars. Guarapuava, Brazil. 2014.

\begin{tabular}{|c|c|c|c|c|c|}
\hline Pear cultivar & EOS** & $\operatorname{lmax} * *$ & Smax** & AUIPC** & AUSPC** \\
\hline Packam's Triumph & $32.38 a$ & $89.50 \quad \mathrm{~A}$ & $61.46 \mathrm{ab}$ & 1762.75 b & $1063.34 \mathrm{bc}$ \\
\hline Rocha & $15.75 \mathrm{ab}$ & $100.00 \mathrm{~A}$ & $77.33 \mathrm{a}$ & 3488.51 a & 1866.30 a \\
\hline Housui & $33.25 \mathrm{a}$ & $66.65 \mathrm{~B}$ & $31.55 \mathrm{c}$ & 1387.50 b & $569.73 \mathrm{c}$ \\
\hline
\end{tabular}

symptoms appearance demonstrates greater resistance to pathogen development.

For the variables Imax and Smax cv. Housui presented the lowest values, differing from the other cultivars (Table 2). Meanwhile, higher Imax values were observed for Cascatense, Packam's Triumph and Rocha pear cultivars, and higher Smax for these last two cultivars. According to Bell and Van Der Zwet (2005), the main European pear cultivars, such as 'Packam's Triumph' and 'Rocha', used in this study are considered susceptible. However, the disease intensity is variable between them. In a similarstudy performed by Gonçalves et al. (2013), comparing the susceptibility of 'Rocha', 'Santa Maria' and 'Abate Fetel' pear to the entomosporiosis leaf spot, considered that all cultivars are susceptible, however 'Santa Maria' obtained higher disease intensities, demonstrating that the genetic effect influences this characteristic. In addition, Gonçalves et al. (2014) also verified that the scion used may interfere in the disease susceptibility.

The cv. Housui presented greater resistance to the pathogen attack with only 33.8 and $30.5 \%$ of the AUIPC of the cultivars with the highest values for incidence and severity, respectively (Table 2). Rocha and Cascatense pear cultivars presented the highest values for the two variables, demonstrating the high susceptibility of these cultivars. Bogo et al. (2013) argue that the severe early defoliation occurred during the summer and caused by this disease reduces the plant photosynthetic capacity, the number of flowering buds and also weakens the plants by reducing vigor and fruit yield. In this sense, Rocha and Cascatense cultivars demand more attention for entomosporiosis control, to reduce the negative effects caused. For Bell \& Van der Zwet (2005) the effective entomosporiosis control requires frequent applications of fungicides during the growth period, especially after periods of leaf wetting.

From these results it is possible to verify that all pear cultivars studied are susceptible to entomosporiosis leaf spot. However, the cultivar Housui demonstrated greater resistance, while the cultivars Rocha and Cascatense presented greater susceptibility to this disease. These results contribute to the characterization of these cultivars in this pathosystem.

\section{References}

Bell, R.L., Van Der Zwet, T. 2005 Host resistance in Pyrus to fabraea leaf spot. Hortscience 40:21-23.

Bogo, A., Casa, R.T., Kretzschamar, A.A., Goncalves, M.J., Correa, D. 2013 Epidemiologia e manejo das principais doenças da Pereira. Revisão Anual de Patologia de Plantas 21:145-161.

Campbell, C.L., Madden, L.V. (Ed.) 1990 Introduction to plant disease epidemiology. Wiley, New York, USA, 532 p.

Fachinello, J.C., Pasa, M.S., Shmtiz, J.D., Betemps, D.L. 2011 . Situação e perspectivas da fruticultura de clima temperado no Brasil. Revista Brasileira de Fruticultura 33:109-120.

Faoro, I.D., Orth, A.I. 2010. A cultura da pereira no Brasil. Revista Brasileira de Fruticultura 32:0-0. 
Fioravanço, J.C. 2007. A cultura da pereira no Brasil: situação econômica e entraves para o seu crescimento. Informações Econômicas 37:52-60.

Goncalves, M.J., Bogo, A., Casa, R.T., Rufato, L., Nicklin, J., Bem, B.P., Kretzschamar, A.A., Grimaldi, F. 2014 Influence of Quince Rootstocks on Entomosporium Leaf Spot (Entomosporium mespili) susceptibility in European Pear cv. Abate Fetel. Journal of Agricultural Science and Technology 4:141-149.

Gonçalves, M.J., Bogo, A., Rufato, L., Jesus Júnior, W.C., Casa, R.T., Weber, G.C., Correa, D. 2013. Behavior of European pear cultivars under different quince rootstocks to Entomosporium leaf spot in southern Brazil. Crop Protection 49:2630.

Jones, A.L., Aldwinckle, H.S. 1990. Compendium of apple and pear diseases. American Phytopathological Society, St. Paul, USA, 100 p.

Machado, B.D., Rufato, L., Bogo, A., Kretzschmar, A.A., Mario, A.E. 2013. Cultivares e portaenxertos sobre o vigor de plantas de pereira europeEOS. Ciência Rural 43:1542-1545.

Llorente, I., Vilardell, A., Vilardell, P., Pattori, E., Bugiani, R., Rossi, V., Montesinos, E. 2010. Control of brown spot of pear by reducing the overwintering inoculum through sanitation. Eur J Plant Pathol.128:127-141.

Rufato, L., Kretzschmar, A. A., Bogo, A. (org.) 2012. A Cultura da pereira. DIOESC, Florianópolis, Brasil, $247 \mathrm{p}$. 